\title{
AN ONLINE INTERCULTURAL EXCHANGE BETWEEN JAPANESE AND SPANISH STUDENTS AND SOME REFLECTIONS FOR FUTURE PROJECTS
}

\author{
Lluís Valls Campà and Juan Manuel Díaz Ayuga² \\ ${ }^{1}$ Kyoto University of Foreign Studies, Japan \\ ${ }^{2}$ Complutense University of Madrid, Spain
}

\begin{abstract}
This poster describes an online intercultural exchange between Japanese and Spanish students of foreign language. With the aim of developing students intercultural communicative competence, during 11 weeks students from both countries discussed in Spanish in online forums about cultural topics. Also, students in Japan did activities in the classroom related to the online activities. Analysis of students' posts in the online forums and their answers to a questionnaire show some positive results. However, many posts had superficial contents and the participation of Spanish students decreased. For future projects, we emphasize the importance of online interaction, offline activities and student's commitment.
\end{abstract}

\section{KEYWORDS}

Cultura Model, Intercultural Communicative Competence, Online Intercultural Exchange, Spanish as a Foreign Language

\section{INTRODUCTION}

Since the last years of the $20^{\text {th }}$ Century, thanks to the diffusion of internet, online intercultural exchanges (OIE) in foreign language teaching have proliferated. These kinds of exchanges have been defined as "the engagement of groups of students in online intercultural interaction and collaboration with partner classes from other cultural contexts or geographical locations under the guidance of educators and/or expert facilitators" (Lewis and O'Dowd, 2016:3). The aims of these exchanges are the development of student's communicative competence in the foreign language and of student's intercultural competence. However, there are no examples of OIE projects between Japanese and Spanish students in the bibliography. In order to test the possibilities of OIE for developing the intercultural communicative competence of Japanese university students of Spanish, we designed and implemented an OIE project between students of Hispanic Studies at a Japanese university and part-time students of Japanese at a Japanese culture center in Spain. The concept of intercultural communicative competence includes not only the linguistic competences, but also intercultural attitudes, intercultural knowledge, skills of discovery and interpreting cultural elements, and a critical cultural awareness (Byram, 1997). This poster (Figure 1) presents our project and its results, and some reflections for future projects.

\section{THE CULTURA MODEL}

The methodology of the course was based on the Cultura model. Its basic idea is that, to understand another culture, it is necessary that students compare their answers to questionnaires (and later other materials) about cultural behaviors, make hypotheses to explain the differences and test them through discussion with students of that culture. For this, Cultura stablishes the next methodological principles: 1) students in both groups should have similar characteristics, 2) both groups must do the same activities and with the same requirements, 3) online forums must be asynchronous, 4) students should use their own language in the online activities, 5) online and offline activities must alternate, 6) the course should last for at least 8 weeks (Furstenberg et al, 2001; Furstenberg and Levet, 2014). 


\section{OUR PROJECT}

Our project took place along 11 weeks, divided in 9 topics, and students from both countries, divided in 6 groups of 9-11 members, interacted in online forums using the platform Canvas. However, it had some differences from Cultura: 1) students from both countries had different language levels, ages and occupations; 2) for Spanish students it was an extracurricular activity; 3) the language of the project was mainly Spanish; 4) only students in Japan did offline activities.

With the example of Unit 2 (on national stereotypes) we describe the process. First, in the classroom Japanese participants studied about stereotyping and learnt vocabulary for this topic. Second, all students answered in Spanish an online questionnaire on stereotypes of Japanese and Spanish people, and compared the answers of both sides. Third, all students discussed about the reasons of the stereotypes in the online forums. Finally, in the classroom, Japanese students presented what they had learnt from their forum discussions, received more information about the topic and discussed in Spanish about it.

\section{RESULTS}

The discourse analysis of online forum discussions found examples of the components of intercultural competence: recognition of stereotypes, asking partners for cultural information, comparing behaviors and making hypotheses to explain them; but, also found many posts with superficial contents. Also, according to a post-project questionnaire, Japanese students think that they got new knowledge about Spanish culture (54.5\%), reflected on Japan (63.7\%), and improved Spanish (91\%). However, the participation of Spanish students decreased, the degree of interaction changed according to the online activities, and students found technical difficulties

\section{CONCLUSION}

We conclude that OIE based on Cultura is a suitable methodology for promoting the intercultural communicative competence of Japanese university students of Spanish, and it can be adapted with some flexibility. However, in order to improve the results of future OIE projects, it is necessary to give more support to Japanese students in the classroom, that participants in both countries do the offline activities, that instructors and students from both sides are committed to the project, that the online platform is easy to use, and that the online and offline activities promote more interaction in the online forums.

\section{REFERENCES}

Byram, R., 1997. Teaching and Assessing Intercultural Communicative Competence. Multilingual Matters, Bristol, UK. Furstenberg, G. and Levet, S., 2014. Cultura: From Then to Now. Its Origins, Key Features, Methodology, and How It Has Evolved. Reflections on the Past and Musings on the Future. In Chun, D.M. (ed.), 2014. Cultura-Inspired Intercultural Exchanges: Focus on Asian and Pacific Languages. National Foreign Language Resource Center, University of Hawai'I, Honolulu, USA.

Furstenberg, G., Levet, S., English, K. and Maillet, K., 2001. Giving a Virtual Voice to Silent language of culture: The Cultura Project. In Language Learning \& Technology, Vol 5, No. 1, pp. 55-102.

Lewis, T. and O'Dowd, R., 2016. Introduction to Online Intercultural Exchange and This Volume. In O'Dowd, R.; Lewis, T. (eds.), 2016, Online Intercultural Exchange. Policy, Pedagogy, Practice. Routledge, New York and London, USA and UK, pp. 3-20. 


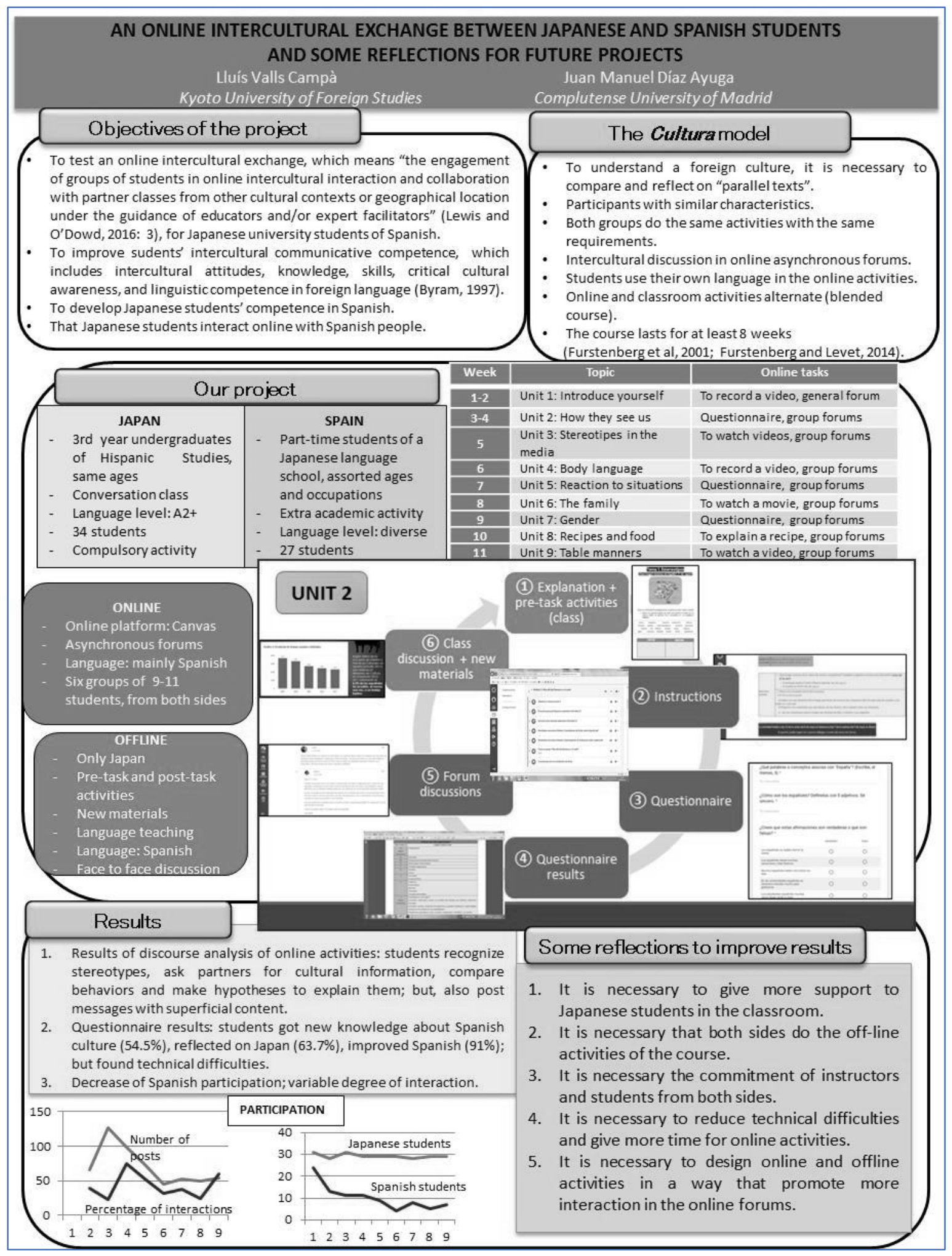

Figure 1. Poster 